\title{
Time Series Analysis of Trend and Variability of Monthly Total Rainfall.
}

\author{
R. Ramakrishna, R.Gautham Goud, Alemayehu Sbhat
}

\begin{abstract}
The long-term variation in rainfall, one of the most important conditions for the climate in a particular region. The purpose of this study was to analysis the total monthly rainfall in the Maychew, which is located in the Tigray region of Ethiopia. The monthly rainfall is on the Maychew meteorological station has been calculated for the period from 2007-2018. The data were analyzed with the help of Minitab-14, R-3.3.1 an Overview of the descriptive statistics and unvaried, Box-Jenkins method, The seasonal ARIMA model was built to analyze the observed data and forecast the total rainfall, after the detection of nonstationarity using the Augmented Dickey-Fuller Test is a Test, and time plot. Some of the main findings of the study indicated that the monthly total rainfall tends to increase. In addition, it was found that, on the basis of the data contained in the history of the last twelve years of age. In addition, the descriptive statistics show that the average amount of rainfall in the Maychew is 58.82. After non-seasonal the first-order differentiation and once seasonal series, differentiation, they will be moved. A time series model for the Maychew Station and was adapted to be processed, diagnostically tested, and ultimately, to be obtained by SARIMA $(3,2,2) *(0,2,2)_{12}$ a model has been created, and this model was used to Forecast the two years monthly values of the total rainfall. The forecasted accumulated rainfall values showed a similar pattern to the previous reports.

Keywords: Box-Jenkins methodology, variability of rainfall, non-stationary, SARIMA
\end{abstract}

\section{I.INTRODUCTION}

$\mathrm{R}$ ainfall is the amount of water falling in rain, snow, etc., during a period of time, and space, usually take the form of a hypothesis to cover the width of the quantity of rain that falls on an area in a particular period of time, so it will fall at different rates in different parts of the world. The variability of the rainfall, it can have an impact on agricultural production, water supply, public transportation, and the economy of the region and of the general population. In regions where there is high volatility from year to year, people often suffer from disasters, as a result of a flood or a drought.

Manuscript received on June 28, 2021

Revised Manuscript received on July 07, 2021.

Manuscript published on July 30, 2021.

* Correspondence Author

R. Ramakrishna*, Professor, Vidya Jyothi Institute of Technology, CB Post, Aziznagar, Hyderabad, India. Email: ramakrishna@vjit.ac.in

R.Gautham Goud, Asst Professor, CVR College of Engineering, Mangalapally, Ibrahimpatan, Hydearabad, India. Email: gautham.goud@cvr.ac.in

Alemayehu Sbhat, Department of Statistics, CNCS, Mekelle University, P.O.Box231, Mekelle, Tigray, Ethiopia. Email: alexsbhat12@gmail.com.

(C) The Authors. Published by Blue Eyes Intelligence Engineering and Sciences Publication (BEIESP). This is an open access article under the CC BY-NC-ND license (http://creativecommons.org/licenses/by-nc$\underline{\mathrm{nd} / 4.0 /)}$ avoided, for the warning, of course, is that it can be useful, (he analysis of the Rainfall data. Agency, the rainfall gradually decreases to around $600 \mathrm{~mm}$ in the north, in areas bordering Eritrea.

There are four seasons in a Ethiopian calendar

In the summer months of June, July and August are summer months. Heavy rain falls during the three-month period.[12]

Autumn (September, October, and November) is in the ring, and also known as the harvest of the season.

Winter (December, January, and February) is the dry season with frost in the mornings, particularly in January.

Spring (March, April and May) is the autumn season and in the rare showers. May is the hottest month in Ethiopia.

Types of Rainfall:

Convective Rainfall: types of Rainfall are caused by the thermal convection due to heating from the surface of the earth. When the land warms up the air above it heats up. This allows the air to rise and rise. As the air rises, it cools

For this type of precondition, the following terms and onditions of existence.

- Abundant flow of water by evaporation into the air, so progressive high electromagnetic radiation emitted by the lar wind. but it can also be in the form of heavy downpours and makes a cumulonimbus cloud.

Orographic rainfall: This is not a form of rainfall which forms when air is blowing out over the sea, and rises to a region of height. This leads to a cooling of the air and the condensation of the moisture in the air, the rain, The conditions for the formation of orographic rainfall arel

- There needs to be a mountain of a barrier in the direction of the wind, so that moist air is forced to go to earth.

- There should be enough moisture in the air incoming moist air, and, as soon as it appears that it is up to the summit of the mountain, the air is usually way down on the other side, heating up. This means that it has a high capacity for water, of water, and, therefore, there is very little rain and on the other side of the mountain.

Natural rainfall is the major source of water for crop production, such as irrigation and contains only about $5 \%$ of the arable land in the country.

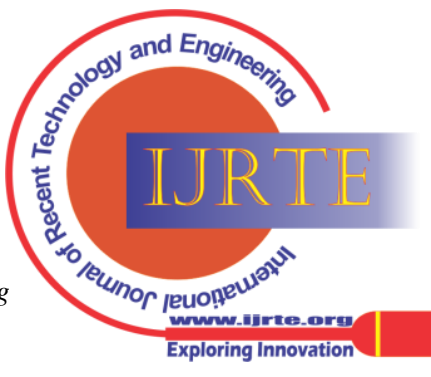


In the southern and south-eastern parts of Ethiopia, in the two dry seasons (December-February and SeptemberNovember). The temporal distribution of the rainfall in these regions show distinct peaks can be separated from each other by a pronounced dry season. Located in the western part of Ethiopia, it is the peak of the rainfall throughout the year.[2] [3]

For, the duration of the rainy period of time is decreasing, and the duration of the dry period increases as you move north in this region, due to the meridional migration of the ITCZ. The appearance of a dry spell which has its own characteristics. It is very important for instagram to agriculture because the rain is one of the most important requirements in the life of plants out in the rain for agriculture. While the information on rainfall patterns in arid regions, it is of great importance for agricultural planning, many of the studies that have made use of it on a seasonal or annual summary of data for trend analysis. However, the farmers ' estimates of the variability of rainfall is related to their farming practices on the basis of the amount, the start and finish times, at intervals of a few days, or even hours, which is not in accordance with the results of the results of the analysis on the basis of a yearly or monthly results. Thus, there is a gap in it for the outcome of the rainfall, the analysis of the control of the local farmers, who are the end users of the results. The understanding of the farmers ' view of can provide important insights into the nature of the ecological processes that cannot be analyzed on the basis of scientific research. However, the studies related to both historical analysis and the opinions of local farmers, and are not available in Ethiopia. Therefore, the aim of this study is to analyze trends and variability of rainfall parameters, as well as the study of the relationship between the results obtained from the analysis of the weather and the rain and the perception of the farmers in the Maychew.[10] [11]

The study population considered is in the seasonal total rainfall was collected by the National Meteorological Agency Service, according to the data of the Mekelle branch, as of January 2007. As of August 2018, the total number of observations is 144.The variables in time series are a benefit of accurate observation, of a quantitative variable are taken at specific time periods or times of the day for each of the seasonal record of the total rainfall value of the predictor variable. The predicted variable is the variable that we are trying to predict, i.e., the seasonal total variability of the rainfall is in the same time.

\section{II.METHODOLOGY}

For the purposes of statistical analysis that will be used is time series analysis. A time series is broadly defined as any set of measurements carried out at different points in time. The aim of this study is both descriptive and inference statistics used for data analysis. Mathematically, the time series is determined by a functional relationship.

$\mathrm{Xt}=\mathrm{f}(\mathrm{t}) \ldots \ldots \ldots \ldots \ldots \ldots \ldots[2.1]$

Where $\mathrm{Xt}$ is the value of the total amount of rainfall at time $\mathrm{t}$, and $\mathrm{t}=\left(\mathrm{t}_{1}, \mathrm{t}_{2}, \mathrm{t}_{3} \ldots \mathrm{t}_{\mathbf{n}}\right.$ with $\left.\mathrm{x}_{1}, \mathrm{X}_{2}, \mathrm{X}_{3}, \ldots, \mathrm{Xn}_{n}\right)$, it follows that the series. [1]

\subsection{Test of Stationary}

Before fitting the model to time series data, then series must be create stationary.

A time series is stationary if the observation Yt, comply with, the following terms and conditions

Published By:
- $\quad$ The non-seasonal variability

- No systematic change in the mean,

- No differentiation is required for the stabilization of the average and the variance

\subsection{Methods of Checking Stationary}

There are a number of different ways to check whether a time series is a stationary and non-stationary.

\subsubsection{Time Plots:}

We see it as a time series graph of our data, and visually check that there are no clear trends in the sector and, depending on the season, and with the help of the sample auto-correlation function (ACF) and partial autocorrelation function (PACF).

\subsubsection{Statistical tests:}

Additionally, we use statistical tests in order to verify that stationary expectations are met or violated. There are a variety of procedures for checking the stationarity of the series, but we have to make use of a Unit root test, and the Augmented Dickey Fuller test (ADF).

\subsubsection{Advanced Dickey Fuller Test (ADF)}

Including lags of the order $\mathrm{p}$, first, the formulation of a higher-order autoregressive process. This means that the length of lag $p$ is to be provided by the use of the test. An alternative approach to the study of information criteria such as the Akaike Information Criterion (AIC) and the Bayesian Information Criterion (BIC).

Testing procedure for the ADF test is a test for the model is: $\Delta \mathrm{Y}_{\mathrm{t}}=\alpha_{0}+\beta_{\mathrm{t}}+\mathrm{cY}_{\mathrm{t}-1}+\alpha_{1} \Delta \mathrm{Y}_{\mathrm{t}-1}+\ldots+\alpha_{\mathrm{e}} \Delta \mathrm{Y}_{\mathrm{t}-\mathrm{e}}+$

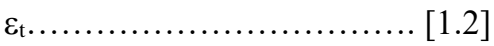

Here $\alpha$ is constant, $\beta$ the time trend coefficient, and $p$ is the lag of the order of the autoregressive process $\left(A_{\mathrm{p}}\right)$. The imposition of restrictions $\alpha=0, \beta=0$ is equivalent to a random walk simulation, and the use of it, there is a limit $\beta$ $=0$ is equivalent to a random walk simulation with drift.

The study has been carried out in the form below:

$\mathrm{H}_{0}$ : The series is non-stationary

$\mathrm{H}_{1}$ :The series is stationary

The Test statistics are set to by $\quad \mathrm{c}=\frac{\hat{\mathrm{Y}}}{S E(\hat{\mathrm{Y}})}$

This test is to be calculated, and is compared with the critical value for the Dickey-Fuller test if the test statistic is less than the critical value, or equivalently, if p-value is greater than the level of significance then the null hypothesis $\mathrm{c}=0$ is rejected, and it is not a unit root.

\subsubsection{Transformations to achieve the stationary}

Transformation is the process of transforming a nonstationary time series into a stationary one. A non-stationary series can be transformed to a stationary series, and with the help of the following methods.

\subsubsection{The data of differentiation:}

That is, given a series we are making a new series. $\Delta Y_{t}=Y_{t}-Y_{t-1}$, here $\Delta Y_{t}$ is the first difference of $Y_{t}$ If the range of the data is non-stationary,

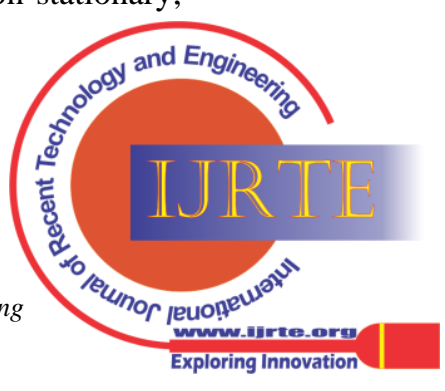


The regular, the differentiation is not able to reach stationarity in the series. That's why we can make use of the seasonal differentiation to achieve stationarity in the series.

If the data contains a trend, which is only a couple of curve to it, and the plot of the residuals of the fit. Since the purpose of the fit, it is easy to remove, with a long-term trend, which is a simple change, such as a straight line, it is most often used.

For the non constant variance, take the logarithm or the square root of a series, you can stabilize the variance. On the negative, you can have a suitable constant to make all of the data is positive for the application of the transformation. This is a constant and can be subtracted from the model to obtain the predicted (i.e., fitted) values, and forecasts for the future of the scores.

\subsubsection{The Seasonal Autoregressive Integrated Moving Average, SARIMA Model (p, d, q) (P, D, Q)s}

SARIMA models are helpful for the modeling of seasonal time series. Where is the mean and other statistics at the same time does not stand still, for many years to come. It was determined that this was a direct extension of and autoregressive integrated moving average (ARIMA) models are presented. SARIMA is used when the time series show seasonal variations. Natural phenomena, such as temperature and rainfall, in the form of snow, and they have a very strong parts that correspond to the time of the year. It is advisable to introduce autoregressive and moving 14average polynomials, which can be identified with the seasonal lags. The resulting net is a seasonal autoregressive moving average model, that is, $\operatorname{ARMA}(\mathrm{P}, \mathrm{Q})_{\mathrm{s}}$, and then take the form.[15]

$\Phi \mathrm{p}\left(\mathrm{B}^{\mathrm{s}}\right) \mathrm{yt}=\theta \mathrm{Q}\left(\mathrm{B}^{\mathrm{s}}\right) e_{t}$

With the following definition of the operators

$\Phi \mathrm{p}\left(\mathrm{B}^{\mathrm{s}}\right)=1-\Phi_{1 \mathrm{~s}} \mathrm{~B}^{\mathrm{s}}-\Phi_{1 \mathrm{~s}} \mathrm{~B}^{2 \mathrm{~s}} \ldots \ldots-\Phi_{\mathrm{Ps}_{\mathrm{s}} \mathrm{B}^{\mathrm{Ps}}}$

$\Theta Q\left(\mathrm{~B}^{\mathrm{s}}\right)=1+\theta_{1 \mathrm{~s}} \mathrm{~B}^{1 \mathrm{~s}}+\theta_{2 \mathrm{~s}} \mathrm{~B}^{2 \mathrm{~s}} \ldots \ldots .+\mathrm{QQ}_{\mathrm{s}} \mathrm{B}^{\mathrm{Qs}}$ are seasonal autoregressive operators, as well as seasonal operator of the moving averages of the orders $\mathrm{P}$ and $\mathrm{Q}$, respectively, with a seasonal period 's' of the signal.

The usual autoregressive and the moving average of the elements are represented by polynomial functions $\alpha(\mathrm{B})$ and $\beta(\mathrm{B})$ the orders of $\mathrm{p}$ and $\mathrm{q}$, respectively, and the seasonal autoregression. and, as a moving average of the elements for the order $\Phi_{P}\left(B^{s}\right)$ and $\Theta_{q}\left(B^{s}\right), \mathrm{P}$ and $\mathrm{Q}$ are Regular and seasonal ingredients, and the difference can be written as: $\nabla^{d}=(1-B)^{d}$ and $\nabla_{s}^{D}=\left(1-B^{s}\right)^{D}$

Where:

$\mathrm{P}$ is the Seasonal autoregressive order

$\mathrm{D}$ is the Seasonal difference order

Q: is the Seasonal moving average order

$\mathrm{S}$ : the Number of time steps in the seasonally adjusted time period

\subsection{Stage in Time Series Model Building}

The ARIMA model for a time series of data from Box and Jenkins for a proposed methodology consists of four steps:[4]

- Model identification

- Estimation of model parameters the non-seasonal autoregressive moving average (ARMA)

- Diagnostic checking for the specified model

- Forecasting

\subsubsection{Model Identification}

This step is to determine the corresponding p,d and $q$ values. For many identification methods, which have been proposed in the literature. The auto-correlation function (ACF),Partial autocorrelation function (PACF), AIC, and $\mathrm{BIC}$, are among the most useful tools in any decent idle time series models, also known as the sequential correlation is the correlation of a signal with a delayed copy of itself as a delay notification feature.

Table 1: The Behavior of the auto-correlation function and partial auto-correlation function

\begin{tabular}{|l|l|l|}
\hline model & ACF & PACF \\
\hline AR(P) & Tail off & $\begin{array}{l}\text { cut off after } \\
\text { lag p }\end{array}$ \\
\hline MA(q) & cut off after lag q & Tail off \\
\hline ARMA(p,q) & Tail off & Tail off \\
\hline
\end{tabular}

The use of auto-correlation and partial auto-correlation functions for the identification and control of the behavior of the time series available in the conditional mean, it is wellestablished. This section is to show that the auto-correlation and partial auto-correlation of a squared process function is useful for the definition of this.[5]

\subsubsection{Parameter Estimation}

If we use the estimates, we have to be careful in choosing the order of the parameters of interest, which is not on the level of significance. If this parameter is not significant, for example, our models are not very useful. In time series analysis, there may be a number of them, however, in this study, we use the Maximum Likelihood (ML) method.

\subsubsection{Diagnostic Test}

After you have selected a time series model, you can use it to evaluate their accuracy in a variety of ways. The usual approach is to extract the data from a series of residue is in accordance with the most recently assigned to the whitenoise sequence, and make sure that the statistical properties of the residuals are in fact compatible with the white noise. Most of the diagnostic tests to deal with all these assumptions are made to determine whether or not the residuals of the modified model are independent and have a constant variance, and are normally distributed.

- $\mathrm{E}(\varepsilon t)=o$

- $\operatorname{Var}(\varepsilon t)=\delta 2$

- $\operatorname{Corr}(\varepsilon t)=$

0 where $\varepsilon t$ is a white noise (residuals)

Various diagnostic statistics and graphs (Q-Q-plot) the residuals can be used for the assessment of the goodness-offit of the tentative model. [13]

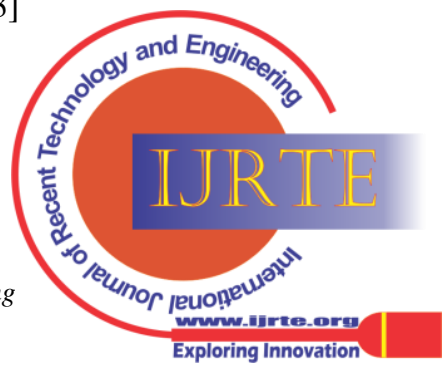




\subsubsection{Ljung-Box Q-Test}

This is a type of statistical test of whether any of a group of autocorrelations of a time series is zero. Instead of checking for the randomness at each distinct lag, it tests the general randomness based on a number of lags, and it is, therefore a portmanteau test.

Hypothesis

$\mathrm{H}_{0}: \rho 1=\rho 2=\rho 3=\ldots \ldots \ldots \mathrm{pk}=0 \mathrm{Vs} . \mathrm{H}_{1}: \rho \mathrm{k} \neq 0$ for at least one $\mathrm{k}=1,2, \ldots, \mathrm{k}\left(\right.$ not $\left.\mathrm{H}_{0}\right)$.

The test statistic

$\mathrm{Q}=\mathrm{n}(\mathrm{n}+2) \sum \frac{\mathrm{r}^{2} \mathrm{k}}{\mathrm{n}-\mathrm{k}} \sim \mathrm{X}_{\alpha}^{2}(\mathrm{k}-\mathrm{p}-\mathrm{q})$,

where $r^{2}$ Is residual autocorrelation and $n$ is number of observation. Reject Ho if $\mathrm{Q} \geq \mathrm{X}_{\alpha}^{2}(\mathrm{k}-\mathrm{p}-\mathrm{q})$. This test statistic is the modified $\mathrm{Q}$ statistic originally proposed by Box and Pierce.[6]

\subsubsection{Forecasting}

At this stage, we will have the ability to predict the future values are based on a fitted model for the forecasting of future events. To predict the goal is to have the ability to predict the future values of a time series of a variable $\mathrm{y}_{\mathrm{t}+\mathrm{k}}, \mathrm{k}=1,2 \ldots$.on the basis of the data collected so far is $\mathrm{y}=$ $\left(\mathrm{y}_{\mathrm{t}}, \mathrm{y}_{\mathrm{t}-1} \mathrm{y}_{\mathrm{t}-2} \ldots . . \mathrm{y}_{1}\right)$

\section{III.RESULTS AND DISCUSSION}

In this study, we examine the data on a monthly time series, observed from January 2007 to December 2018. The total number of observations is 144 . The discussion begins with a description of the data and the results of the model selection process. The results are explained and discussed. Finally, the total monthly rainfall at Maychew to proceed. The statistical software package, that is used for the majority of the analysis, the R-3.3.1 and Minitab 14.

\subsection{Descriptive Statistics}

Some of the descriptive statistics such as mean, median, standard deviation, minimum, and maximum values of the total monthly rainfall, are presented in table 2 below.

Table 2: Descriptive statistics for Maychew Monthly total rainfall data.

\begin{tabular}{|c|c|c|c|}
\hline Variable & $\mathbf{N}$ & Mean & StDev \\
\hline Minimum & Maximum & & \\
\hline Monthly total rainfall & 144 & 58.82 & 67.45 \\
\hline 33.05 & 297.90 & & \\
\hline
\end{tabular}

The data presented in Table 4.1 above, the total of the amount to the minimum and, in general, the maximum rainfall is in May, and $0.0 \mathrm{~mm}$, and $297.90 \mathrm{~mm}$. The average amount of rainfall in Maychew, and for twelve years was 58.82 .

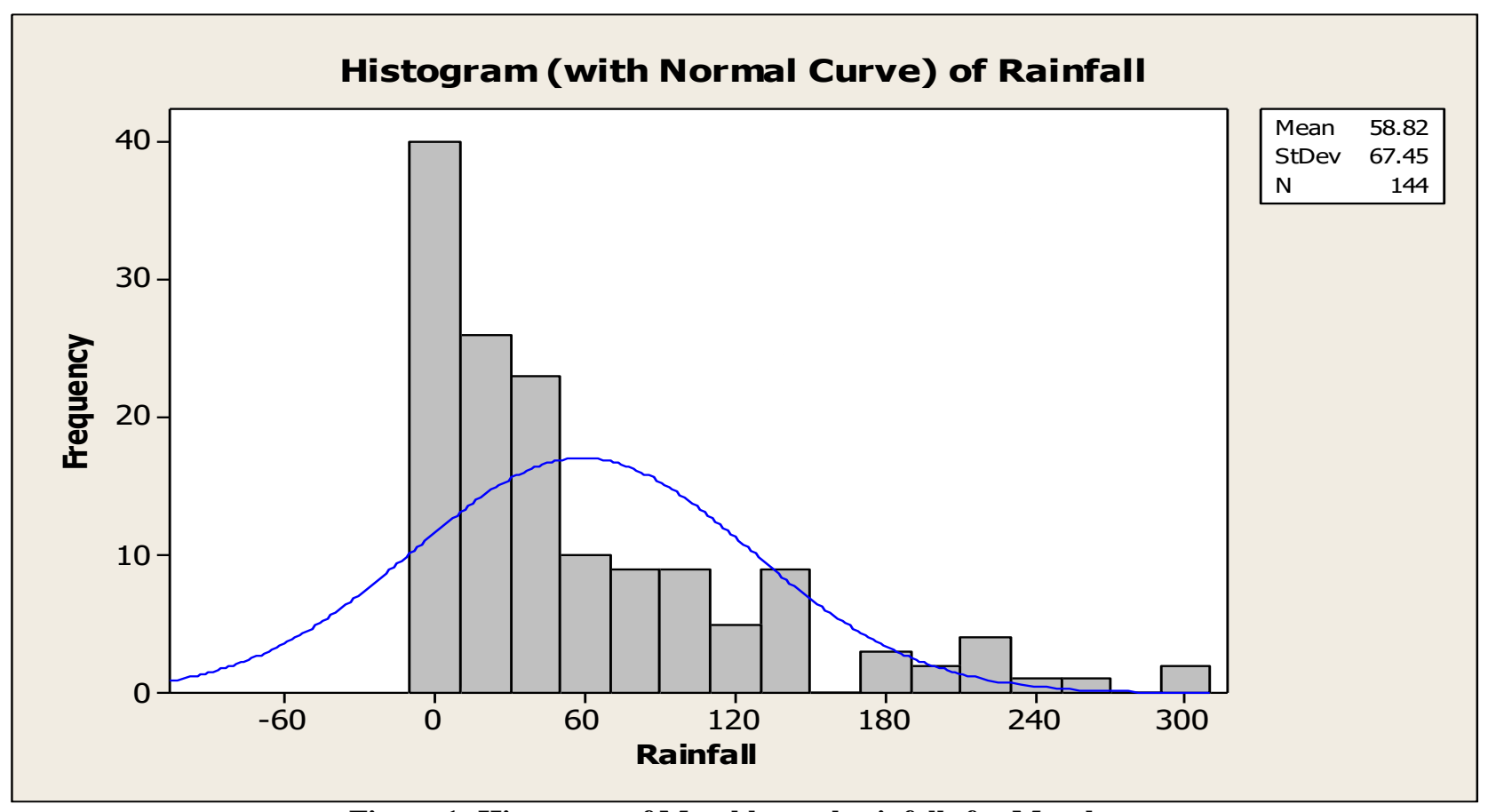

Figure 1: Histogram of Monthly total rainfalls for Maychew

As we can see from this histogram, it Maychew's monthly total rainfall over the past twelve years as a highrainfall-frequency 0 to 55 millimetres, which shows that the lower the frequency of the monthly rainfall varies between 170 and 300 millimeters, the details of this series are approximately normally distributed and right skewed.

\subsection{Decomposing Seasonal Data}

A seasonal and a time-series trend component, a seasonal component irregular component. Decomposing the time series mean of the distribution of the total of the monthly indicator in each of these three components.

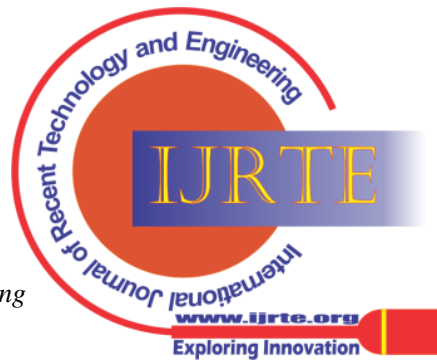




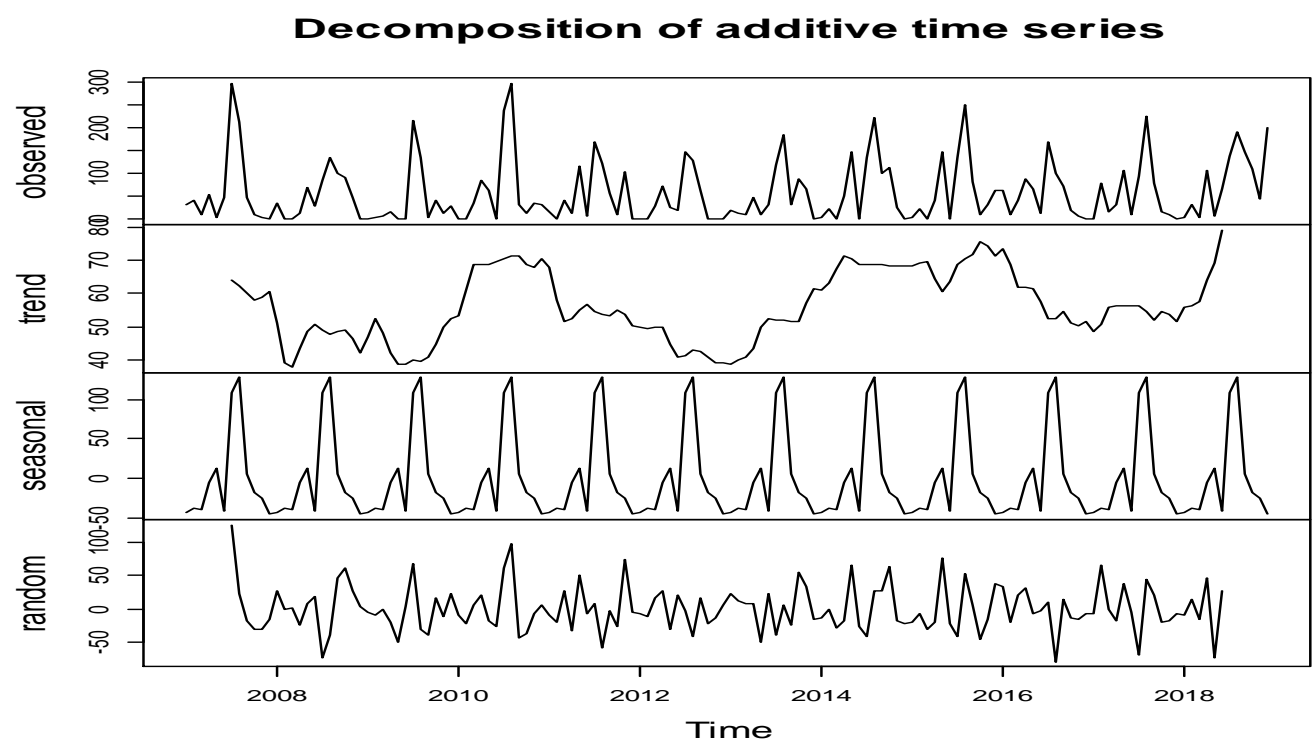

Figuure 2: Seasonal Decomposetion of total monthly rainfall in Maychew

The chart above shows the seasonal distribution of the total monthly rainfall in Maychew, the original time series (top), the estimated trend component, (the second from the top), the estimated seasonal component (third from top), and the estimate of the irregular component (at the bottom). From the graph, we can see that there is a seasonal and trend effects. So,the evaluation of the trend component, the correct component to the season of the time-series

\subsection{Testing Stationary}

If, there is not a constant, mean and the variance in the time series, it needs to change seasonally difference until it becomes stationary. With the help of the time plot and was supplemented by the Augmented Dickey-Fuller test the original series is non-stationary, and it has to be a differential lock.

\subsubsection{Augmented Dickey-Fuller Test}

The test is that the series is non-stationary verses stationary. We are ready to test the null hypothesis, with the help of the eAugmented Dickey-Fuller Test (ADF). This test is used to find out whether or not there is an original series from the stationary or not.

Table 3: Augmented Dickey-Fuller test for original series.

\begin{tabular}{|l|l|l|l|}
\hline \multicolumn{4}{|c|}{ Augmented Dickey-Fuller Test when } \\
\hline Variable & Dickey-Fuller & Lag order & p-value \\
\hline original series & -2.1497 & 24 & 0.5141 \\
& & & \\
\hline
\end{tabular}

The data presented in table 3 show that, testing of stationary for original series of our data. Since the p-value of the test is to have a $5 \%$ significance level, is it not, that we can reject the null hypothesis that the means that the series really needed to differentiation of a (non-stationary). According to the results shown in Table 3, the null hypothesis, which states that the data must be a differential lock.

Table 4: The Augmented Dickey-Fuller tests for the difference series.

\begin{tabular}{|l|l|l|l|}
\hline \multicolumn{4}{|l|}{ Augmented Dickey-Fuller Test } \\
when $\mathrm{d}=1$ and $\mathrm{D}=1$
\end{tabular}

\begin{tabular}{|l|l|l|l|}
\hline \multicolumn{4}{|c|}{ Augmented Dickey-Fuller Test } \\
when $\mathrm{d}=2$ and $\mathrm{D}=2$
\end{tabular}

The results are presented in table 4 show that the seasonal and diverse grade to be stationary at the $5 \%$ significance level, Alpha, since the p-value is less than Alpha. After that, we will be able to each and every request, because they're at a stationary.

\subsubsection{Time plot}

In addition, we can see that in this graph, it is more compressed than the original plot of the series, with the following features. (See Figure 3) of the graph, we can see that the highest total rainfall was recorded in 2018, and the lowest in 2007 and 2011, which indicates the presence of non stationary in the original series, during the period. Also, the oscillation of the mean is very similar to the seasonally in the different series. [8]

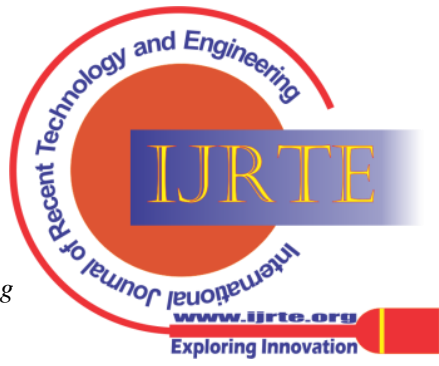




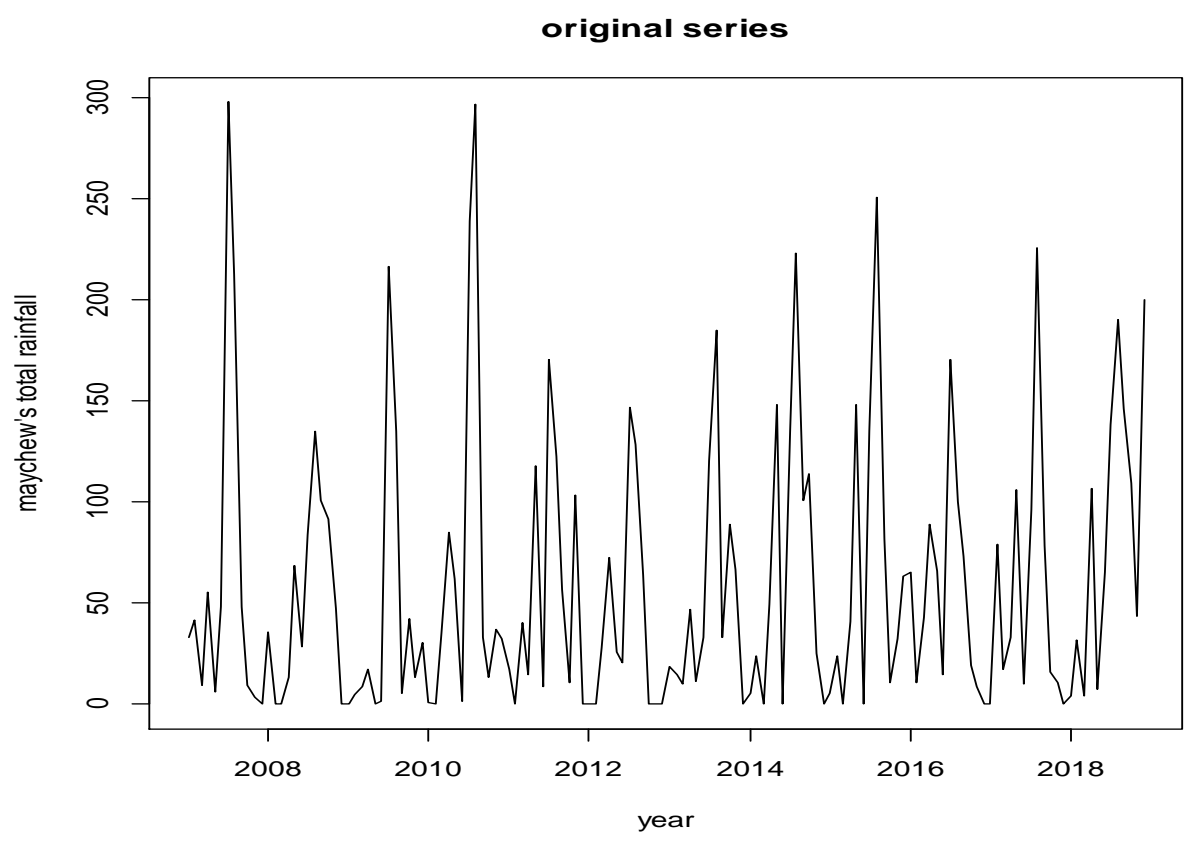

Figure 3: Time-series graphs of the monthly rainfall for the maychew the original series

\subsubsection{Decomposing Seasonality}

A seasonal time series consists of a trend component, a seasonal component and an irregular component. Decomposing the time series means separating the total monthly Rainfall into these three components. In the graph below (Figure 4) shows the seasonal decomposition of the total monthly rainfall in Maychew, that is, the original time series (top), the estimated time component, (the second from the top), the estimated seasonal component (the third from left), and the estimate of the irregular component (at the bottom). From the graph, we can see that there is a seasonal time series and trends in the time series. Therefore, in order to have a satisfactory stationary assumption, we need to eliminate the seasonal and trend effects of their data. We can make the appropriate correction to the total monthly rainfall in Maychew, the estimate of the seasonal component, and subtracting the estimated seasonal component from the original time series for the estimation of the trend component, a seasonal component from the data by differentiating, or to correct the one below (Figure 5).

\section{Decomposition of additive time series}

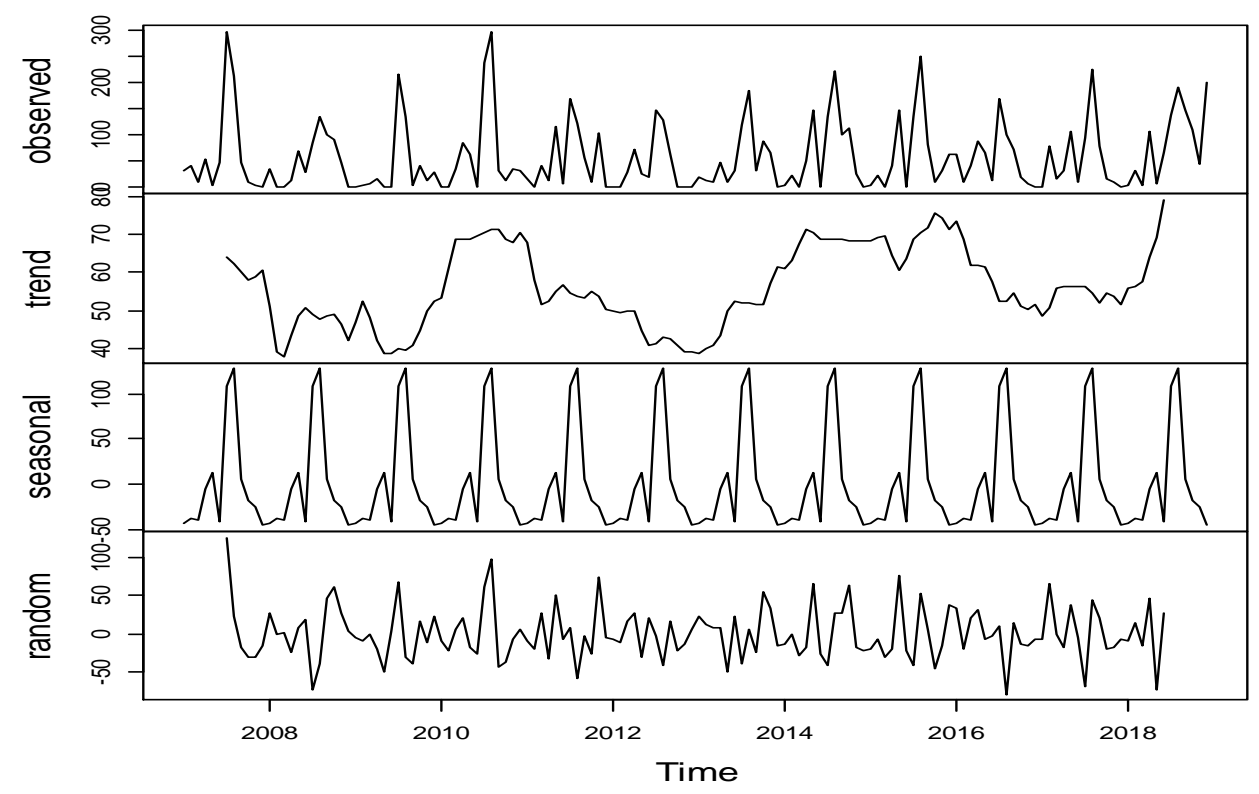

Figure 4: seasonal decomposetion of total monthly rainfall in Maychew

Published By:

Blue Eyes Intelligence Engineering

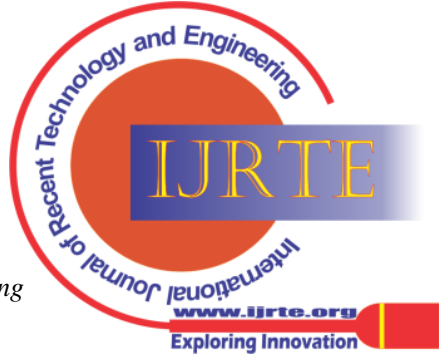


Decomposition of additive time series

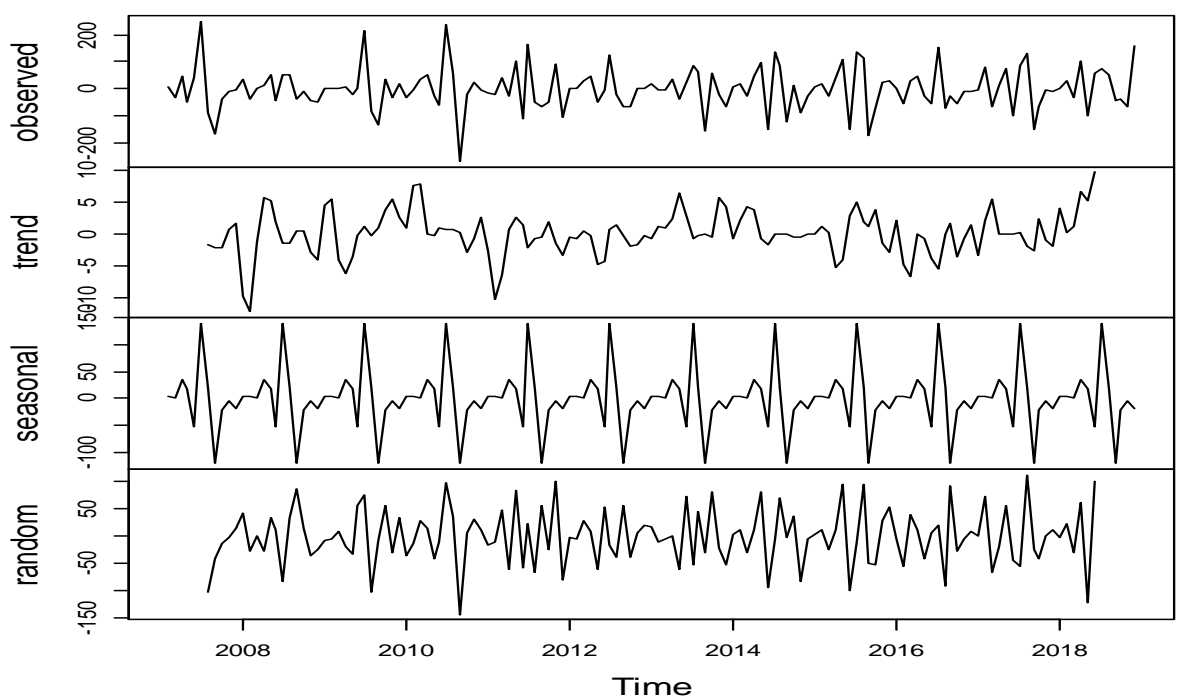

Figure 5: adjusted components of total monthly rainfall in Maychew
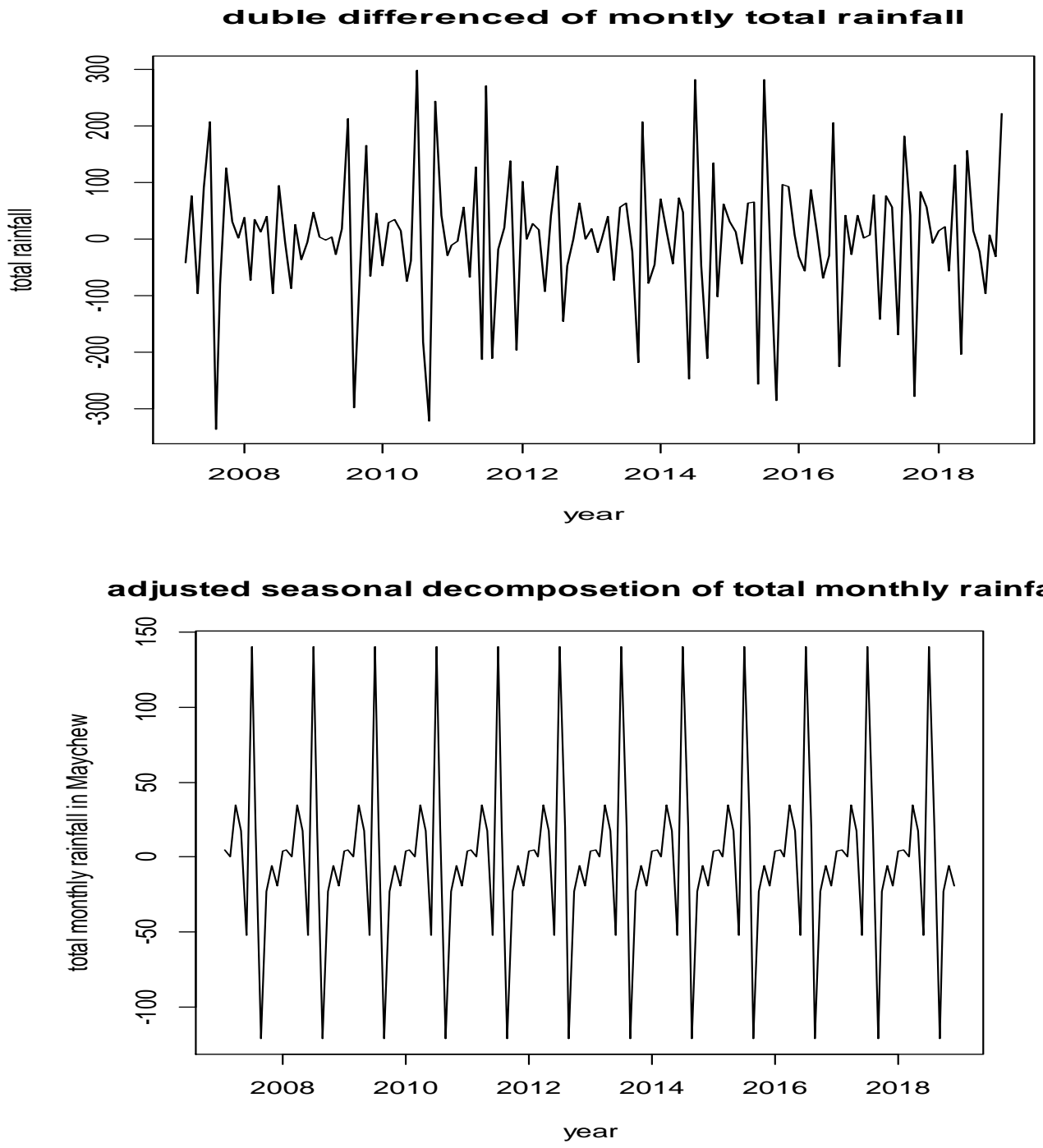

Figure 6: adjusted seasonal decomposetion of total monthly rainfall in Maychew

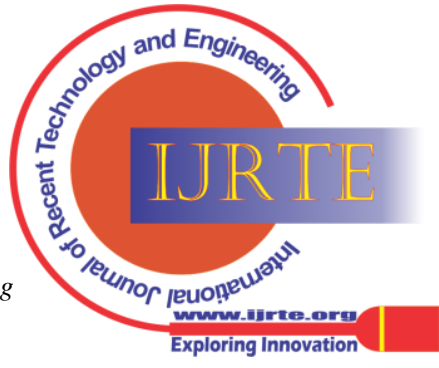




\subsection{Model Identification}

As soon as you can, the degree of the difference is determined, autoregressive and moving-average orders of magnitude were carried out by the research, the sample autocorrelations and the sample partial autocorrelations. The use of the sample auto-correlation and sample partial autocorrelation functions for the preliminary identification of the model parameters, ACF, and PACF should be taken into account. With the help of a reference point for the data presented in Table 5, the initial values of p, q, P, Q. Since we are dealing with estimates, it is not clear whether the sample ACF or PACF tailing off or cutting off. In addition, the two models are apparently different, but it's actually very, very similar. At this stage, you will have a different set of points $\mathrm{p}, \mathrm{q}$, and $\mathrm{P}, \mathrm{Q}$ are the values for the control, and then you are ready to start the process of evaluating the parameters.[15]
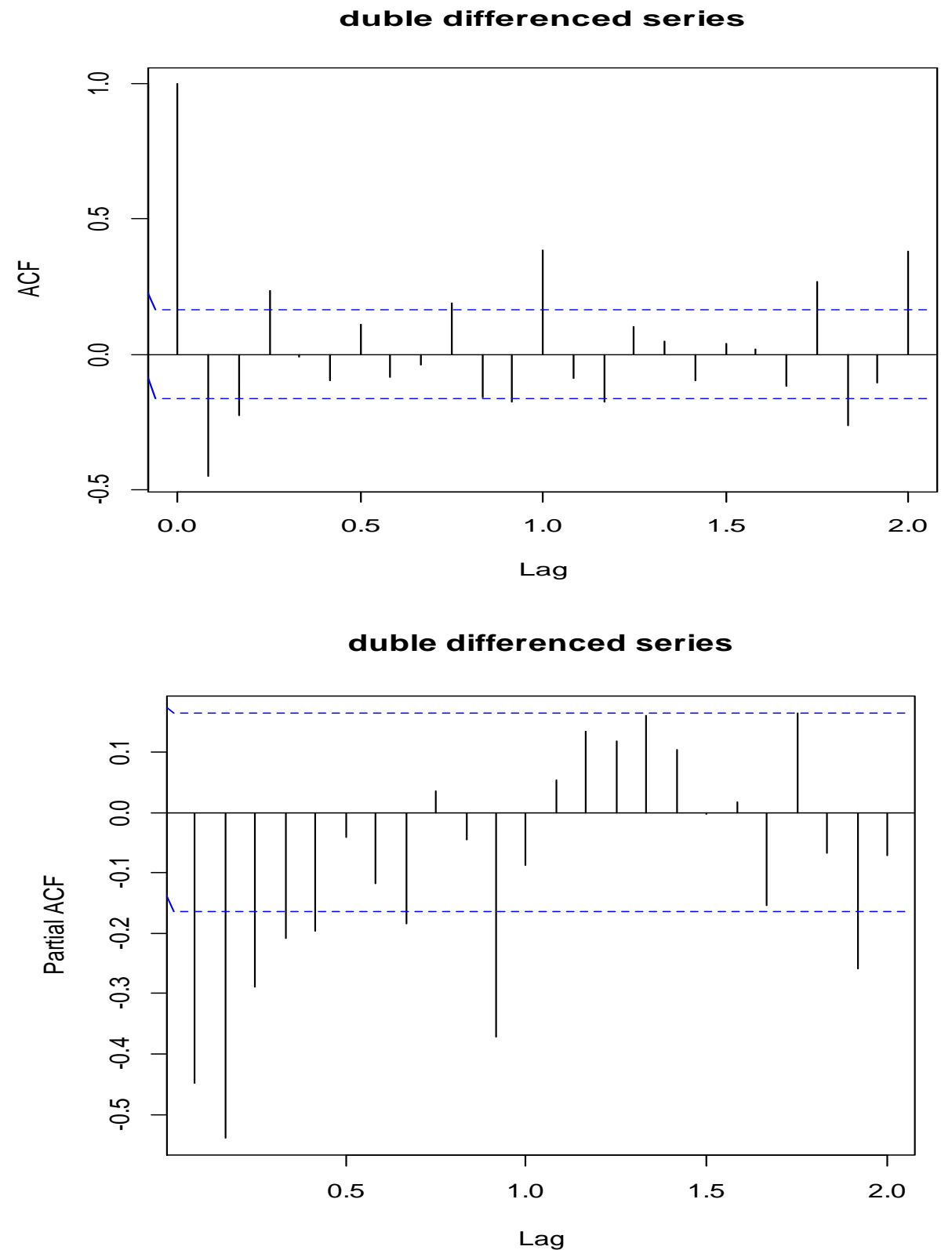

Figure 7: ACF and PACF seasonally differenced series of monthly total rainfall for maychew.

Figure 7 shows that the ACF with at lag- 0.0 differs significantly from zero, since the spikes are beyond the scope of the confidence limit. Thus, the non-seasonal MA of orders $0,1,2,3,4$, and 5 . In addition, it has been the seasonal MA term occurs at lags, shall multiples of 12 . It has 5 significant series, following a lag-1.0 in ACF, in this context, hence, the possible orders of seasonal MA term are 0, 1, 2, 3, 4 and 5. Similarly, significant spikes in the PACF indicated possible non-seasonal AR terms. Hence, the order of non-seasonal term possible values are 0,1,2, 3, 4,5 and 6 and the order of the seasonal terms, it is one of the important places, after a lag of 1 . they are about the size of 1 (i.e. 0, 1), there is a significant increase was 1.5 in the PACF. After you set up the available models, we can select the best model using AIC.

Published By:

Blue Eyes Intelligence Engineering

and Sciences Publication

(C) Copyright: All rights reserved.

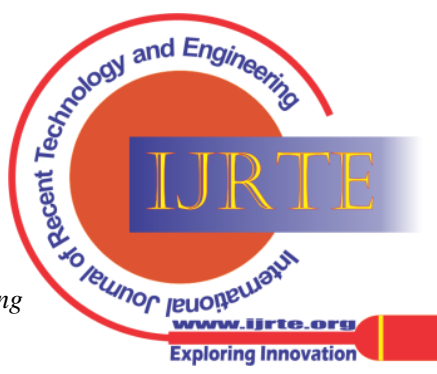


Table 5: AIC Model selection for total rainfall data

\begin{tabular}{|l|l|c|}
\hline $\begin{array}{l}\text { SARIMA(p, d, } \\
\text { q)*(P, D, Q)12 }\end{array}$ & $\begin{array}{l}\text { log } \\
\text { likelihood }\end{array}$ & AIC \\
\hline$(6,2,5) *(1,2,5)_{12}$ & -817 & 1332.22 \\
\hline$(4,2,3) *(0,2,3)_{12}$ & -654.14 & 1330.29 \\
\hline$(3,2,2) *(0,2,2)_{12}$ & -653.41 & 1322.82 \\
\hline$(2,2,1) *(0,2,1)_{12}$ & -684.08 & 1378.17 \\
\hline$(1,2,0)^{*}(0,2,0)_{12}$ & -786.06 & 1576.12 \\
\hline$(0,2,1) *(1,2,0)_{12}$ & -722.83 & 1451.67 \\
\hline$(0,2,2) *(1,2,1)_{12}$ & -665.1 & 1340.19 \\
\hline$(1,2,4) *(1,2,3)_{12}$ & -652.76 & 1325.53 \\
\hline$(2,2,4)^{*}(1,2,4)_{12}$ & -651.45 & 1326.9 \\
\hline$(3,2,5) *(1,2,5)_{12}$ & -651.18 & 1332.37 \\
\hline
\end{tabular}

The data presented in Table 5, in terms of the criteria that will be used by the Akaike information criteria's (AIC), the tentative model is then used to obtain a better match SARIMA information( $3,2,2) *(0,2,2)_{12}$ because it has the lowest AIC value, which is 1322.82 in comparison to the others.

\subsection{Parameter Estimation}

As soon as the Order-of SARIMA $(3,2,2) *(0,2,2)_{12}$ given a model, the next step is the eestimation of the parameters. The estimated parameters of the SARIMA (3, 2, $2) *(0,2,2)_{12}$ the $\mathrm{R}$ output is displayed, as shown below. Coefficients: \begin{tabular}{cccccc}
\multicolumn{2}{c}{ ar1 } & ar2 & ar3 & ma1 & ma2 \\
sma1 sma2 $^{\text {0.0787 }}-0.0724$ & 0.0755 & -1.8892 & 0.9222 & - \\
$1.8149 \quad 0.9826$ & & & &
\end{tabular}

$\begin{array}{llllll}\text { s.e. } & 0.1148 & 0.1051 & 0.1051 & 0.0547 & 0.0596\end{array}$

$0.1715 \quad 0.1815$

$\operatorname{sigma}^{\wedge} 2$ estimated as 2110: $\log$ likelihood $=-653.41$, aic $=$ 1322.82

\subsection{Diagnostic Checking}

In this matter, how well the selected model is consistent with the actual monthly rainfall data, and the model is fit to the data, which is used by a user and a model residuals are random .As a result, several diagnostic statistics and plots, of which the remains may be used for the assessment of the goodness of a SARIMA matching $(3,2,2) *(0,2,2)_{12}$ in the data model. At this stage, it is the plot of the standardized residuals of the series. If it's a good fit for the data, and the standard residuals should behave in the same way as an identically and independently distributed sequence with a mean of zero and a variance of one. The time plot to be verified at any warranties, representations or apparent deviations from this assumption.To manage the scheduling of an industry-standard method of a given type of SARIMA model, which is shown in the figure. 8 is shown below.[7][14][16]

\section{Standardized Residuals}

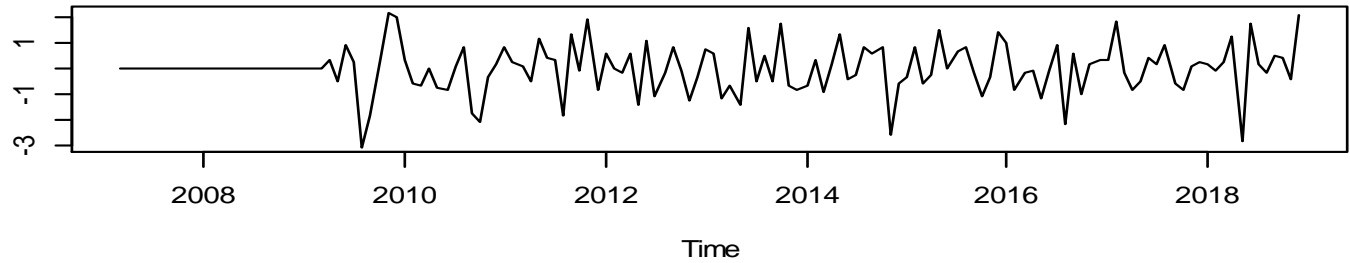

ACF of Residuals

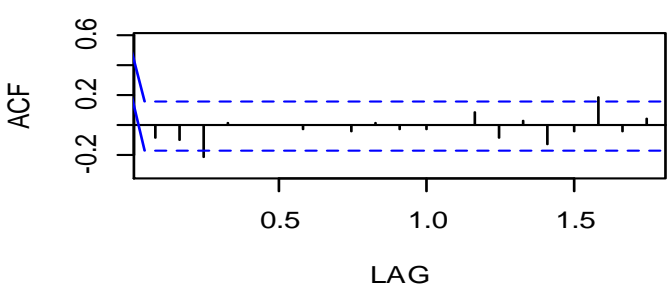

Normal Q-Q Plot of Std Residuals

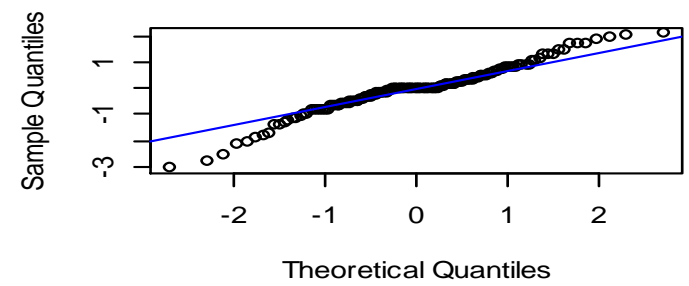

p values for Ljung-Box statistic
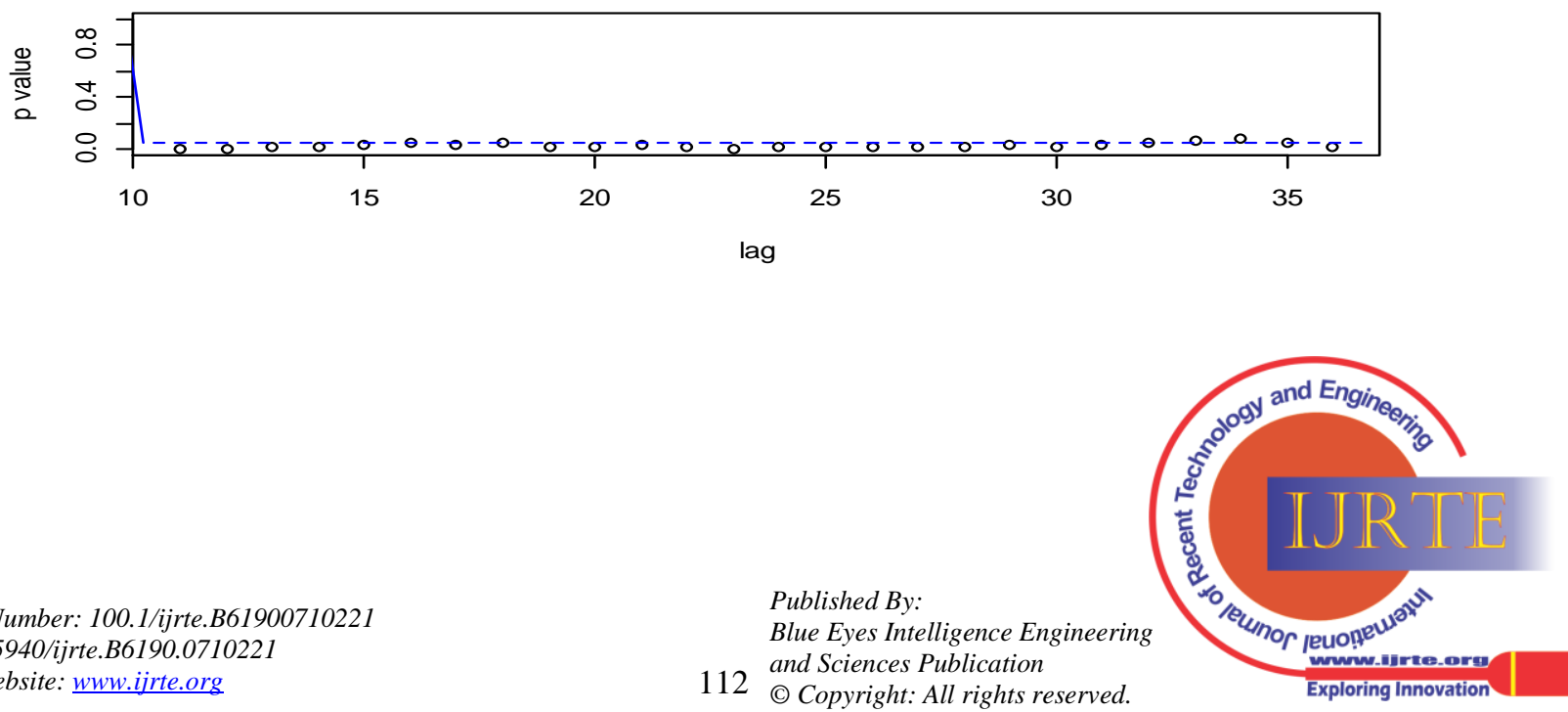

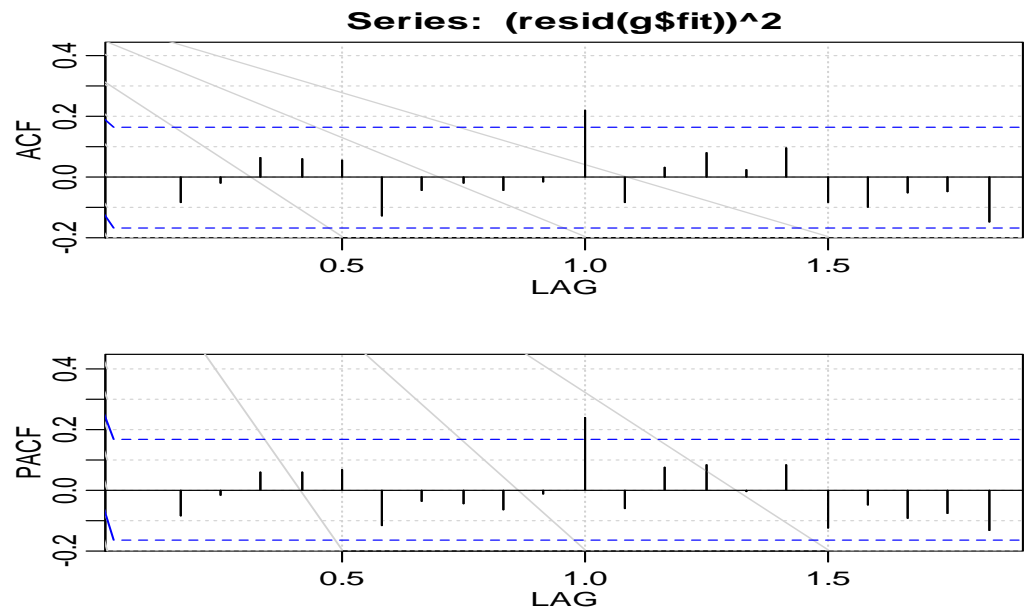

Figure 8: Diagnostics of the residuals from the fitted model

3.6.1. Ljung-Box Q-statistic: A formal test is used to check whether a series of independent or not, and the testing of these hypotheses can be made to evaluate the suitability of the model for the selection of the significance level, and then compare it with the value of the calculated chi-square critical value. The Q-statistics are computed and are shown in the table below

Table 6: Ljung-Box test for residuals of the fitted model

\begin{tabular}{|l|l|l|l|l|}
\hline \multirow{2}{*}{$\begin{array}{l}\text { Box-Ljung } \\
\text { test }\end{array}$} & Q-statistic & DF & P - value & $\begin{array}{l}\text { Lag- } \\
\text { value }\end{array}$ \\
\cline { 2 - 5 } & 5.9949 & 10 & 0.2121 & 24 \\
\hline
\end{tabular}

The data presented in Table 5, we observed that the pvalue is greater than 0.05 , i.e. it $0.2121>0.05$, which means that it's the white noise hypothesis is not rejected.

3.6.2. Normality test: The normality of the residuals was determined using the Shapiro-Wilck test . In the output below you can see the p-value is greater than 0.05 , which indicates that the fitted model residuals are Normally Distributed, with the focus of attention.

Table-7: Shapiro-wilk test for the normality test of residuals of the fitted model

\begin{tabular}{|l|l|l|}
\hline Shapiro-Wilck & Test Statistic & p-value \\
\cline { 2 - 3 } Test statistic & 0.98587 & 0.1512 \\
\hline
\end{tabular}

\subsection{Forecasting}

Because the design of the diagnostic tests show that the parameter estimates are significant and the residual series is white noise, and the evaluation, monitoring, and diagnosis of the stages of the simulation process are completed. Now, we can proceed to the Forecasts of a series of one-processed by a SARIMA $(3,2,2) *(0,2,2)_{12}$ it is a model. and let's look at the graph below.

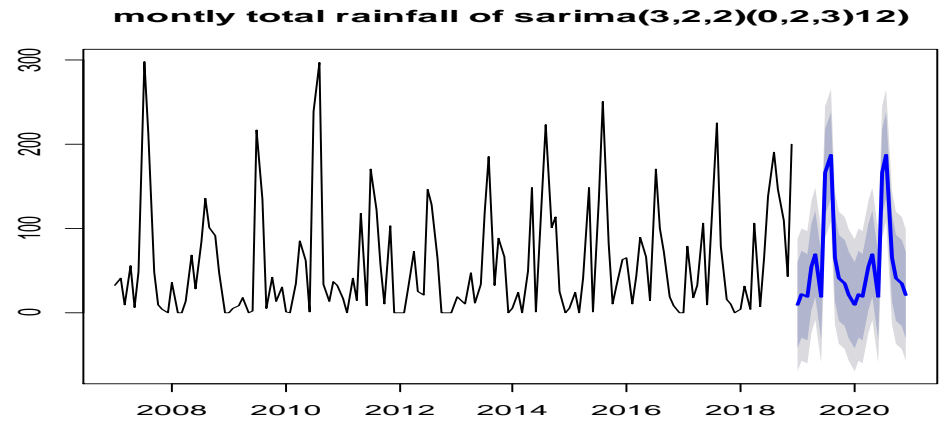

Table 8: Forecasted total rainfall of 2019 and 2020 years using SARIMA $(3,2,2) *(0,2,2) 12$

\begin{tabular}{|l|l|l|l|l|l|l|l|l|l|l|l|l|}
\hline Year & Jan & Feb & Mar & Apr & May & Jun & Jul & Aug & Sep & Oct & Nov & Dec \\
\hline 2019 & 9.24 & 22.02 & 18.68 & 54.43 & 69.79 & 11.27 & 166.88 & 58.84 & 187.13 & 41.38 & 35.2 & 21.15 \\
\hline 2020 & 11.02 & 24.32 & 20.63 & 56.48 & 21.79 & 19.27 & 169 & 60.77 & 85.40 & 50.69 & 30 & 101.12 \\
\hline
\end{tabular}

\subsubsection{Accuracy of Forecast}

The accuracy of forecasts, it is usually measured with the help of the root-mean-square error (RMSE), mean absolute error (MAE) and mean absolute percentage error (MAPE). The results show that the mean error (ME) is -0.342 , the Average of the absolute standard error
(MASE) is 0.75 , which is a relatively good day for the error table is estimated by the output of the $r$, then we can see that the forecast is correct.

Published By:

Blue Eyes Intelligence Engineering 


\begin{tabular}{|c|l|l|l|l|}
\hline ME & MAE & MASE & ACF1 \\
& RMSE & & & \\
\hline-.0342 & 39.97 & 29.48 & 0.75 & 0.047 \\
\hline
\end{tabular}

\section{CONCLUSION AND RECOMMENDATIONS}

\subsection{Conclusions}

This study analyzed the monthly rainfall records in the twelve-year period, using data from Mekelle city station, in particular for the study of the total rainfall pattern in Mekelle City. The Box-Jenkins methodology was used for the SARIMA model to the data. It was found that the structure of the total monthly rainfall in May 2007 to 2018, with a relative trend of structure, which is very, very low growth rate.The stationarity of the total rainfall is confirmed by time plot as well as the use of ADF test. However, the regular co-rainfall values were recorded throughout the year, so the attendance of the season, during the time in which the series is observed for the time plot of the series and the nonstationarity is to be resolved first non-seasonal differencing of seasonal differencing. In accordance with the procedures of the SARIMA Box-Jenkins model, the different proposed models have been developed. However, on the basis of the calculated AIC values for each of the proposed models, the best model is provided as a SARIMA $(3,2,2) *(0,2,2)_{12}$. On the other hand, the analysis of the model was carried out by means of a careful analysis of the model residuals. It was found that the model of the residuals follow a white noise process with mean zero and a constant variance, and were uncorrelated. In addition, it was found that the model residuals are normally using the Shapiro-Wilck-test. On the properly recognized and the good prediction of the future, the total rainfall is in the Maychew, the forecasted values of the total rainfall showed a similar pattern to the previous reports.[9]

\subsection{Recommendation}

The effects of changes in rainfall may exacerbate existing social and economic problems in the region, especially those that depend on resources that are sensitive to the variability of the rainfall and on summer rain-fed in agriculture. Improved ability to cope with future extreme rainfall variability, it can reduce the size of the social, economic and human losses. Rainfall is one of the most critical climatic conditions in the region. Recorded meteorological data from the rainfall, the analysis indicates that there is no decreasing trend has been observed. The resulting decrease in rainfall will lead to an increase in droughts. For this reason, governments, or academics who are willing to do this, you need to take into account the variability of the rainfall in carrying out further research in this area, and, if possible, in the development of a climate change adaptation strategy.

\section{REFERENCES}

1. Anderson, T.W. (1971).The statistical Analysis of time series, John Wiley \& Sons, New York.

2. Awulachew SB, Erkossa T, Namara RE (2010). Irrigation potentia in Ethiopia: Constraints and opportunities for enhancing the system. Unpublished Report to the Bill and Melinda Gates Foundation.

3. Bewket W.Conway D. (2007). Note on the temporal and spatial variability of rainfall in the drought prone Amhara Region of Ethiopia Int. J. Climatol. 27: 1467-1477 basis of the preliminary diagnosis is carried out, and if

4. Box, G.E.P. and Jenkins, G.M. (1976). Time Series Analysis, Forecasting and Control. Revised Edition, Holden Day, San Francisco.

5. Box G. E. P, G. M. Jenkins, and G. C.Reinsel.(2008) Time Series Analysis: Forecasting and Control. Wiley, New York, $5^{\text {th }}$ edition.

6. Box, G. E. P. and Pierce, D. A. (1970), "Distribution of the Autocorrelations in Autoregressive Moving Average Time Series Models", Journal of the American Statistical Association, 65 1509 1526.

7. Chatfield, C. (1991), "The Analysis of Time Series: An Introduction", $5^{\text {th }}$ ed., Chapman and Hall, London.

8. Braganza K, Karoly DJ, Arblaster JM. (2004). Diurnal temperature rangeas an index of global climate change during the twentieth centuryGeophys. Res. Lett. 31(13): L13217.

9. Gebre Hadgu1, Kindie Tesfaye, Girma Mamo and Belay Kassa (2013) Trend and variability of rainfall in MAYCHEW Northern Ethiopia: Analysis of meteorological data and farmers' perception , Academia Journal of Agricultural Research 1(6): 088-100

10. Fekadu Bekele,(1997), Ethiopian Use of ENSO Information in Its Seasonal Forecasts, Journal of African Studies

11. GebreHadgu May (2013).Trend and variability of rainfall: research paper, northern Ethiopia.

12. Meze-Hausken, Seleshi and Zanke(2004)Rainfall characteristics in dry land areas and critical for agricultural planning: many studies usedseasonal or annualtotals for trend analysis.

13. P. J. Brockwell and R. A. Davis,.(1991) Time Series: Theory and Methods. Springer-Verlag, New York, 2nd edition.

14. Ramakrishna, R., Naveen Kumar, B, M. Krishna Reddy.M. (2012), “Neural Networks Forecasting Model for Monthly Electricity Load in Andhra Pradesh",International Journal of Engineering and Research Applications ,Vol. 2, Issue 1,Jan-Feb 2012, pp11081115,ISSN:2229-5046.

15. Robert H. Shumway ,David S. Stoffer, (2010). Time Series Analysis and Its Applications With R Examples, Springer. Pittsburgh, PA

16. William W.S Wei (2006). Time Series Analysis: Univariate and Multivariate Methods,Journal of the American Statistical Association. 33(1)DOI:10.2307/2289741 ISBN: 978-0-201-15911-0

\section{AUTHOR PROFILE}

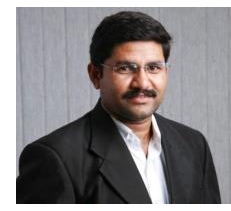

Dr. Ravi. Ramakrishna, is a Professor in Statistics VJIT (A), Hyderabad. He has completed Ph.D. (Statistics) from Osmania University in 2011. He has more than 16 years of experience in VJIT, Hyderabad and 4 years of experience in Abroad and has published about 13 research papers to his credit from peer-reviewed journals and conferences. His research interests include Time series, Queuing Theory and Neural networks. He is an Editorial Board Member in various reputed International Journals.

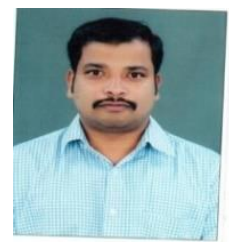

R.Gautham Goud, is working as a Asst. Prof. of statistics in CVR College of Engineering since 2013 and has 19 years of teaching experience. He has submitted Thesis of Ph.D in Statistics from Osmania university under the guidance of Prof. M. Krishna Reddy, recently. He has published about 4 research papers to his credit from peer-reviewed journals and conferences. He Carried out a UGC sponsored Minor Research Project titled "Statistical study of the relationship between Inflation and Economic Growth in India"

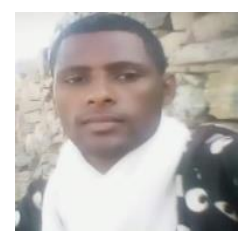

Alemayehu Sbhat, is a Statistics student of Mekelle University, Mekelle, Ethiopia. Presently, he doing his own Business at Debre Markos, Ethiopia.

Published By:

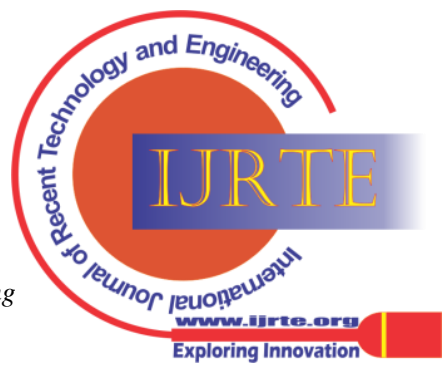

